Article

\title{
Antioxidant Properties and Neuroprotective Capacity of Strawberry Tree Fruit (Arbutus unedo)
}

Sofia Fortalezas ${ }^{1}$, Lucélia Tavares ${ }^{1}$, Rui Pimpão ${ }^{1}$, Meenu Tyagi ${ }^{1}$, Vera Pontes ${ }^{1}$, Paula M. Alves $^{2}$, Gordon McDougall ${ }^{3}$, Derek Stewart ${ }^{3}$, Ricardo B. Ferreira ${ }^{1,4}$ and Cláudia N. Santos ${ }^{1, *}$

1 Disease \& Stress Biology, Instituto de Tecnologia Química e Biológica, Universidade Nova de Lisboa, 2781-901 Oeiras, Portugal; E-Mails: fortalezas@itqb.unl.pt (S.F.);

1tavares@itqb.unl.pt (L.T.); pimpaorc@itqb.unl.pt (R.P.); tyagi@itqb.unl.pt (M.T.);

vpontes@itqb.unl.pt (V.P.); rbferreira@itqb.unl.pt (R.B.F)

2 Animal Cell Technology Unit, Instituto de Tecnologia Química e BiológicaUniversidade Nova de

Lisboa/Instituto de Biologia Experimental e Tecnológica, 2781-901 Oeiras, Portugal;

E-Mail: marques@itqb.unl.pt

3 Plant Products and Food Quality Programme, Scottish Crop Research Institute, Dundee, DD2 5DA, Scotland, UK; E-Mails: Gordon.McDougall@scri.ac.uk (G.M.); Derek.Stewart@scri.ac.uk (D.S.)

4 Departamento de Botânica e Engenharia Biológica, Instituto Superior de Agronomia, Universidade Técnica de Lisboa, Tapada da Ajuda, 1349-017 Lisboa, Portugal

* Author to whom correspondence should be addressed; E-Mail: csantos@itqb.unl.pt.

Received: 16 December 2009 / Accepted: 9 February 2010 / Published: 21 February 2010

\begin{abstract}
Berries contain significant amounts of phytochemicals, including polyphenols, which are reported to reduce cancer risk, coronary heart disease and other degenerative diseases. These effects are mainly attributed to the antioxidant capacity of polyphenols found in berries. Strawberry tree (Arbutus unedo) berries are used in folk medicine but seldom eaten as fresh fruits. Their phenolic profile and antioxidant capacity reveal a high potential, but they are not well characterized as a "health promoting food". The aim of this study was to assess the antioxidant properties of the edible strawberry tree fruit in vitro and in a neurodegeneration cell model. Raspberry (Rubus idaeus), a well documented healthpromoting fruit, was used as a control for comparison purposes. A. unedo yielded a similar content in polyphenols and a slightly lower value of total antioxidant capacity in comparison to $R$. idaeus. Although the chemically-measured antioxidant activity was similar between both fruits, $R$. idaeus increased neuroblastoma survival in a
\end{abstract}


neurodegeneration cell model by $36.6 \%$ whereas $A$. unedo extracts caused no effect on neuroblastoma viability. These results clearly demonstrate that a promising level of chemically-determined antioxidant activity of a plant extract is not necessarily correlated with biological significance, as assessed by the effect of $A$. unedo fruit in a neurodegeneration cell model.

Keywords: polyphenols; flavonoids; antioxidants; neuroprotection; strawberry tree

\section{Introduction}

Aerobic cellular metabolism continuously produces reactive oxygen species (ROS) with concomitant potential for mutagenic and oncogenic effects. The imbalance between ROS and endogenous plus exogenous antioxidants induces oxidative stress, characteristic of some diseases, however diet provides natural antioxidants present in many fruits and vegetables that may participate in disease prevention.

There is epidemiological evidence that insufficient intake of fruits and vegetables may predispose the human body to a range of chronic health disorders, including cancer and cardiovascular disease [1]. Fruits are a rich source of antioxidants, especially polyphenols [2], which may protect against damage caused by ROS. Intake of fruits like berries seems to have a range of beneficial effects, from inhibition of cancer to alleviation of neurodegeneration [3].

Neurodegenerative diseases involve a complex set of oxidative reactions leading to neuronal cell death. Central nervous system cells are able to combat oxidative stress using some limited resources: vitamins, bioactive molecules, lipoic acid, antioxidant enzymes and redox sensitive protein transcriptional factors. However, this defense system can be activated/modulated by nutritional antioxidants such as polyphenols. Flavonoids have been reported to have substantial neuroprotective activity [4-7]. These effects have been attributed to their general free radical trapping capacity, or antioxidant activity per se, on neurons, but they also intervene in multiple biological processes, such as iron chelation, activation of survival genes, cell signaling pathways and regulation of mitochondrial function $[1,2]$.

Strawberry tree (Arbutus unedo L.; Ericaceae family) is an evergreen shrub, a native Mediterranean species that is also cultivated in other regions of Eastern Europe [8]. Its fruits are spherical, about $2 \mathrm{~cm}$ in diameter, dark red, and tasty only when fully ripe in autumn. A. unedo berries are rarely eaten as fresh fruits, but have some importance in local agricultural communities where they are used for the production of alcoholic beverages, jams, jellies and marmalades [9,10]. The fruits are also used in folk medicine as antiseptics, diuretics and laxatives, while the leaves have long been employed as an astringent, diuretic, urinary anti-septic agent and, more recently, in the therapy of hypertension and diabetes [11]. Together with its traditional applications, the wide range of antioxidants in strawberry tree fruit, such as phenolic compounds (e.g. anthocyanins, gallic acid derivatives and tannins ), vitamin C, vitamin E and carotenoids [8-10,12,13], suggest a potentially high value as a "health promoting food". However, the biological significance of these in vitro-detected antioxidant properties remains to be determined. It is therefore of considerable interest to validate the bioactivities of $A$. unedo fruits in 
cell/organism-based assays to assess their potential therapeutic effect against a wide range of human diseases.

In this work, the antioxidant properties of the edible fruit from $A$. unedo were tested. Raspberry (Rubus idaeus) was used as a control for comparison purposes, since it is a well documented antioxidant fruit with recognized biologically significance effects [14-16]. Their total polyphenol and anthocyanin contents were measured and their antioxidant potential was assessed by measuring the antioxidant capacity for one of the most relevant free radicals for humans, the peroxyl radical. Their phenolic composition was also checked by LC-MS.

The biological activity of $A$. unedo fruit phytochemicals (at known non-toxic levels) was further characterized using a more specific bioactivity assay, performed on a neurodegeneration cell model. Peroxides are often used as models to induce oxidative damage in cells cultured under in vitro conditions [17]. To this end, the neurodegeneration cell model consisted of a human SK-N-MC neuroblastoma cell line which was submitted to an oxidative injury by hydrogen peroxide $\left(\mathrm{H}_{2} \mathrm{O}_{2}\right)$. The neuroprotective capacity of $A$. unedo and $R$. idaeus fruit extracts were evaluated and compared by the increase in cell viability detected when extract pre-conditioning was performed before the oxidative insult.

\section{Results and Discussion}

\subsection{Total Phenols, Anthocyanins and Peroxyl Scavenging Activity}

Hydroethanolic extractions were performed on each fruit, $A$. unedo and $R$. idaeus, and the yield was determined. The extract yield was higher for $A$. unedo $(79 \%, \mathrm{w} / \mathrm{w})$ than for $R$. idaeus $(47 \%, \mathrm{w} / \mathrm{w})$. The total content in phenols was determined (Table 1). A. unedo extract yielded a similar content of total phenolics (16.46 $\left.\pm 3.66 \mathrm{mg} \mathrm{GAE} . \mathrm{g}^{-1} \mathrm{dw}\right)$ to $R$. idaeus $\left(13.23 \pm 0.94 \mathrm{mg} \mathrm{GAE} . \mathrm{g}^{-1} \mathrm{dw}\right)$. Content in total phenols are in the range of values described in the literature for A. unedo and R. idaeus $[9,18,19]$. Phenolic compounds previously identified in strawberry tree fruits were mainly gallic acid derivatives, anthocyanins and proanthocyanidins, which are highly active as antioxidants [20]. Within these groups of antioxidant compounds, proanthocyanidins were the most abundant, representing more than $80 \%$ of the total flavonoid content [10]. The phenolic composition obtained for strawberry tree fruits used in this work (see supplementary data, Table 1 and Figure 1) was similar to the reported bibliography. We also detected some quercetin and ellagic acid derivatives as minor components. The raspberry extracts gave LC-MS profiles similar to previous work [14] and were dominated by anthocyanins and ellagitannins (see supplementary data, Table 3 and 4 and Figure 2), with a number of other minor components.

Anthocyanins are a group of phenolic compounds of great interest in nutrition and medicine because of their potent antioxidant capacity and possible protective effects on human health [21]. The total anthocyanin content of raspberry was much higher than strawberry tree fruits (Table 1). Three main anthocyanins (cyanidin-3- $O$ - $\beta$-D-galactopyranoside, delphinidin-3- $O$ - $\beta$-D-glucopyranoside and cyanidin-3-O- $\beta$-D-arabinopyranoside; see supplementary data, Table 2 and Figure $1 \mathrm{C}$ ) were seen in A. unedo fruits which agrees with previous reports [12]. On the other hand, the most abundant $R$. idaeus anthocyanins are usually cyanidin-3-O-sophoroside, cyanidin-3-O- $\left(2^{\mathrm{G}}\right)$-glucosylrutinoside, cyanidin-3- 
$O$-glucoside, pelargonidin-3- $O$-sophoroside, cyanidin-3- $O$-rutinoside and pelargonidin-3- $O-\left(2^{\mathrm{G}}\right)$ glucosylrutinoside. Lower amounts of pelargonidin-3-O-glucoside and pelargonidin-3-O-rutinoside were also detected [14]. The raspberry extracts used in this study differed from reported anthocyanin compositions (e.g. [14]) with the dominant anthocyanins being cyanidin-3-O-sophoroside and cyanidin-3-O-rutinoside, probably as a result of varietal differences (see supplementary data, Table 4 and Figure 2C).

Table 1. Total phenol, anthocyanin content and antioxidant activity of $A$. unedo and $R$. idaeus fruits.

\begin{tabular}{|l|l|l|l|}
\hline Fruit & $\begin{array}{l}\text { Total phenol content } \\
\left(\mathrm{mg} \mathrm{GAE} \mathrm{g}^{-1} \mathrm{dw}\right)\end{array}$ & $\begin{array}{l}\text { Anthocyanin content } \\
(\mathrm{mg} \text { cy-3-glucoside. } \\
\left.100 \mathrm{~g}^{-1} \mathrm{dw}\right)\end{array}$ & $\begin{array}{l}\text { Antioxidant activity } \\
\left(\mathrm{mmol} \text { TE. } 100 \mathrm{~g}^{-1} \mathrm{dw}\right)\end{array}$ \\
\hline A. unedo & $16.46 \pm 3.66$ & $76.26 \pm 9.85^{* * *}$ & $11.66 \pm 2.01$ \\
\hline R. idaeus & $13.23 \pm 0.94$ & $438.60 \pm 12.20$ & $15.37 \pm 2.73$ \\
\hline
\end{tabular}

Each value is the average of three independent replicates \pm SD. $* * *$ - significantly different values for $\mathrm{p}<0.001$.

Based on their high phenol content, it was possible to reasonably anticipate a high antioxidant activity for both $A$. unedo and $R$. idaeus berries. The antioxidant capacity, assessed by ORAC, was similar for both fruits $\left(11.66 \pm 2.01 \mathrm{mmol} \mathrm{TE} .100 \mathrm{~g}^{-1} \mathrm{dw}\right.$ for strawberry tree fruit and $15.37 \pm 2.73$ mmol TE. $100 \mathrm{~g}^{-1} \mathrm{dw}$ for raspberry). Antioxidant capacities reported in the literature are difficult to compare due to differences in the methodologies used. However, García-Alonso and co-workers determined the antioxidant activity of 27 fruits, including strawberry tree and raspberry, and established a ranking (TEAC method) where strawberry tree antioxidant capacity was ranked slightly higher than that of raspberry [22].

Both $A$. unedo and $R$. idaeus berries have been characterized as good sources of antioxidants, with their antioxidant properties associated to different groups of compounds. For A. unedo, this activity is attributed to the high flavonoid content, (mainly comprised by proanthocyanidins, cyanidin and delphinidin glycosides), ellagic acid and its diglucoside derivative, vitamin $\mathrm{C}$ and $\mathrm{E}$ and carotenoids [10]. $R$. idaeus studies performed with an ellagitannin-rich fraction show that this fraction had considerably higher antioxidant capacity than the original raspberry extract or an anthocyanin-rich fraction [14], a observation already noted by others [23]. Over $50 \%$ of the total raspberry antioxidant capacity is conferred by Sanguiin H6 and Lambertianin C [23].

Knowledge of the chemically-determined antioxidant characterization of $A$. unedo berries is certainly important. However, its biological significance remains to be evaluated. It is therefore crucial to validate these bioactivities on different cell-based human-disease models assays and, at the end, in the overall organism.

\subsection{Effect of Fruit Extracts on a Neurodegeneration Cell Model}

Based on promising in vitro antioxidant results, a neuroprotective test was performed using an SKN-MC human neuroblastoma cell line. Firstly, a non-toxic range of concentrations of raspberry and strawberry tree fruit extracts were defined. Toxicity tests involved the determination of cell viability 
after a $4 \mathrm{~h}$ incubation in the range 0 to $500 \mu \mathrm{g}$ GAE. $\mathrm{mL}^{-1}$ medium. No toxic effects were observed in cell viability until $125 \mu \mathrm{g}$ GAE. $\mathrm{mL}^{-1}$ for both fruits, as shown in Figure 1. For concentrations higher than $125 \mu \mathrm{g}$ GAE. $\mathrm{mL}^{-1}$, the viability decreased, particularly with raspberry, probably because the compounds become toxic for cells. This phenomenon should happen since many plant secondary products seem to have a paradoxical (hormetic) effect on diseases that depend on their concentration and thus level of consumption [24]; at low concentrations a compound could exert a benefic effect, but when its concentration is too high for the organism/cells it starts to be toxic [25-27].

Figure 1. Cytotoxicity evaluation of $A$. unedo and $R$. idaeus extracts in the neuroblastoma cell line SK-N-MC. Cell viability was determined with $3.45 \times 10^{5}$ cells/well in the range of 0 to 500 ․ㅡ﹎.GAE. $\mathrm{mL}^{-1}$ medium, using the CellTiter-Blue ${ }^{\circledR}$ Cell Viability Assay. $\diamond A$. unedo - R. idaeus. Each point is the average of three independent replicates. Vertical bars represent $\pm \mathrm{SD}$.

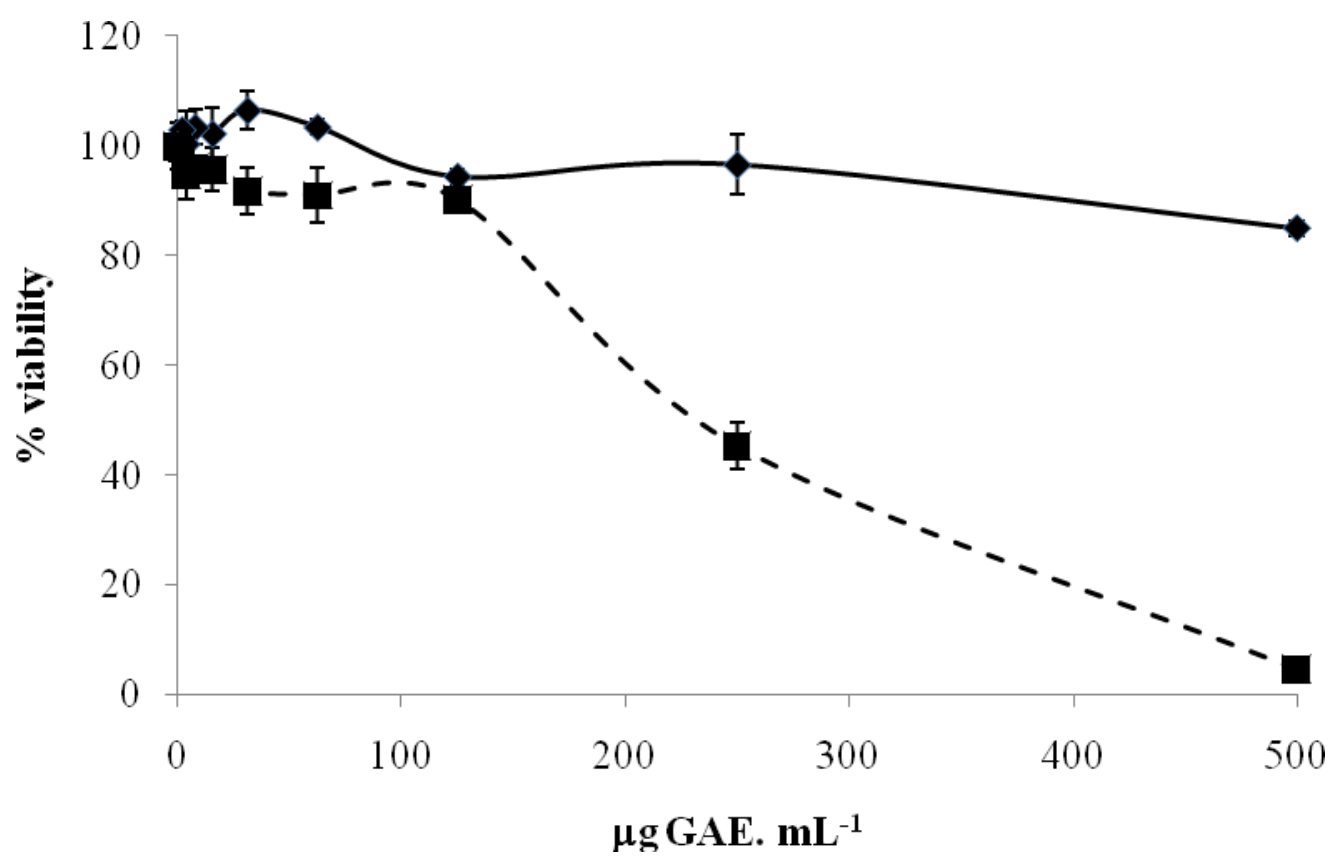

To evaluate the neuroprotective effect of the fruit extracts, the neuroblastoma cell line SK-N-MC was submitted to an oxidative stress after a pre-incubation with the dried fruit extracts solubilized in medium. Peroxides are often used as models to induce oxidative damage in cells cultured under in vitro conditions [17]. To this end, the ability of hydrogen peroxide $\left(\mathrm{H}_{2} \mathrm{O}_{2}\right)$ to induce oxidative stress in SK-N-MC cells was assessed by the cell viability test already described above. Non-toxic concentrations of the fruits extracts were used in the SK-N-MC cells challenged with $1 \mathrm{mM} \mathrm{H}_{2} \mathrm{O}_{2}$ to evaluate the neuroprotection capacity of the phytochemicals. This test evaluates the cytoprotective activities of the compounds, by protecting cell viability after pre-conditioning the cells with the extracts before the oxidative injury.

Although the chemically-measured antioxidant activity exhibited by strawberry tree fruit was slightly lower from that of raspberry, the raspberry extract rescued cell survival while no significant effect in neuroblastoma viability was detected with the strawberry tree berry extract, using the same amount of polyphenols, estimated by Folin- Ciocaulteau method (Figure 2). 
Figure 2. Effect of $A$. unedo and $R$. idaeus fruit extracts on cell viability after $\mathrm{H}_{2} \mathrm{O}_{2}$ insult SK-N-MC cells were treated with $1 \mathrm{mM} \mathrm{H}_{2} \mathrm{O}_{2}$ for $1.5 \mathrm{~h}$ after $1 \mathrm{~h}$ pre-conditioning with the fruit extracts. Assay was performed with $2.8 \times 10^{5}$ cells/well as described in methods, and cell viability was determined using the CellTiter-Blue ${ }^{\circledR}$ Cell Viability Assay. ( $\square$ ) 0

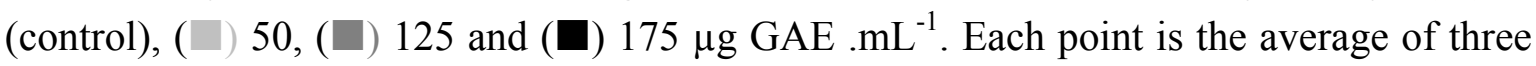
independent replicates. Vertical bars represent $\pm \mathrm{SD}$. ** - significantly different values for $\mathrm{p}<0.01$.

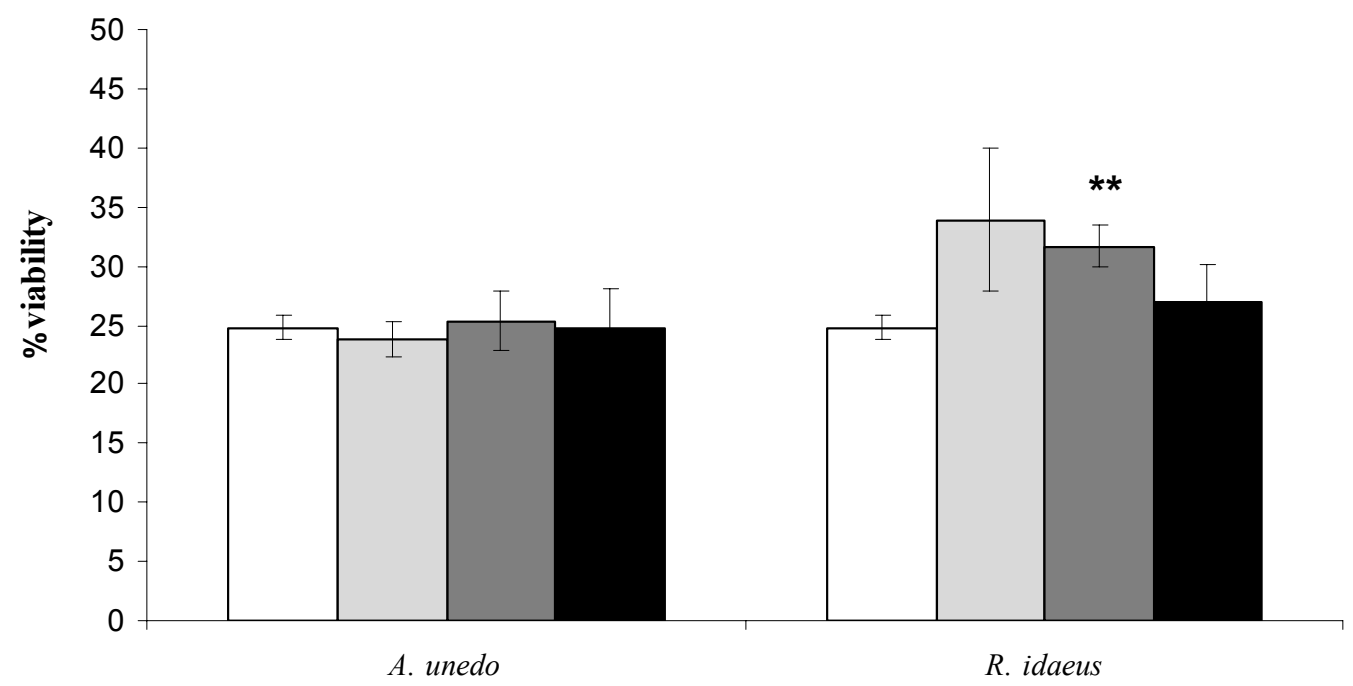

In fact, the incubation of the human cells with $1 \mathrm{mM} \mathrm{H}_{2} \mathrm{O}_{2}$ for 1.5 hours reduced viability to $25 \%$, whereas pre-incubation with $R$. idaeus extract enhanced cell survival to $33.8 \%$. In other words, the overall increase in cell viability with $R$. idaeus was estimated as $36.6 \%$ at $50 \mu \mathrm{g} \mathrm{GAE}$. $\mathrm{mL}^{-1}$ and $27.8 \%$ at $125 \mu \mathrm{g}$ GAE. $\mathrm{mL}^{-1}$, but decreased for higher concentrations $\left(8.9 \%\right.$ at $\left.175 \mu \mathrm{g} \mathrm{GAE} . \mathrm{mL}^{-1}\right)$.

Both $R$. idaeus and A. unedo fruits are potential sources of bioactive compounds like vitamin $\mathrm{C}$, phenolic acids, proanthocyanidins and flavonol derivatives, however the absence of cell protection detected for $A$. unedo suggests that its phytochemical composition is not effective against $\mathrm{H}_{2} \mathrm{O}_{2}$ stress induced in this neuroblastoma cell models, but does not exclude biological effectiveness in other systems. These fruits are qualitatively quite different in their chemical composition which could explain the different bioefficacy in protecting cells from oxidative stress. In fact, the biological effects presented by $R$. idaeus fruits could be attributed to ellagitannin content (not present in A. unedo) and the higher levels of anthocyanins.

This study is a good example of the importance in evaluating the biological function of phenolics to validate their in vitro antioxidant activity. Further assays in different biosystems will be performed to validate the biological effects of $A$. unedo phytochemicals. 


\section{Experimental Section}

\subsection{Biological Material}

Arbutus unedo L. fruits were collected in November 2007, by random sampling in an extensive area of Arrábida Natural Park (southern region of Portugal). The samples were immediately ground and freeze dried and stored at $-80^{\circ} \mathrm{C}$ prior to extraction. Rubus idaeus cv. Polka was grown in Herdade Experimental da Fataca, Odemira, Portugal.

\subsection{Extract Preparation}

To each $1 \mathrm{~g}$ of lyophilized powder, $12 \mathrm{~mL}$ of hydroethanolic solvent (ethanol $50 \%(\mathrm{v} / \mathrm{v})$ ) were added and the mixture was shaken for $30 \mathrm{~min}$, at room temperature in the dark. The mixture was then centrifuged at 12,400 $\mathrm{g}$ during $10 \mathrm{~min}$ at room temperature. The supernatant was filtered through paper filter and then through $0.20 \mu \mathrm{m}$ cellulose acetate membrane filters. The resulting extracts were stored frozen at $-80{ }^{\circ} \mathrm{C}$, no longer than one month. For each fruit extract, an aliquot was freeze dried under vacuum conditions and the yield was determined.

\subsection{Total Phenolic Measurement}

Determination of total phenolic compounds was performed by the Folin-Ciocalteau method [28]. Briefly, to each well of a microplate, $235 \mu \mathrm{L}$ water, $5 \mu \mathrm{L}$ sample (or solvent, in the control), $15 \mu \mathrm{L}$ Folin-Ciocalteau's reagent (Fluka ${ }^{\circledR}$ ) and $45 \mu \mathrm{L}$ saturated $\mathrm{Na}_{2} \mathrm{CO}_{3}$ were added. The microplate was incubated for $30 \mathrm{~min}$ at $40{ }^{\circ} \mathrm{C}$ and the absorbance at $765 \mathrm{~nm}$ measured. Gallic acid was used as the standard and the results were expressed in $\mathrm{mg}$ of gallic acid equivalents per $\mathrm{g}$ of dry weight of plant material (mg GAE. $\mathrm{g}^{-1} \mathrm{dw}$ ).

\subsection{Anthocyanin Content}

The total anthocyanin content of the fruit extracts was determined using a $\mathrm{pH}$ differential absorbance method [18]. Absorbance readings were related to anthocyanin content using the molar extinction coefficient of 12100 calculated for cyanidin-3-O-glucoside. Results were expressed as mg of cyanidin 3-glucoside equivalents per $100 \mathrm{~g}$ of dry weight of plant material (mg cy-3-glucoside. $\left.100 \mathrm{~g}^{-1} \mathrm{dw}\right)$.

\subsection{Peroxyl Radical Scavenging Capacity Assay}

Peroxyl radical scavenging capacity was determined by the ORAC (Oxygen Radical Absorbance Capacity) method [19,29]. Briefly, the reaction mixture contained $150 \mu \mathrm{L}$ of sodium fluorescein $(0.2 \mathrm{nM})$ (Uranine, Fluorescein Sodium Salt ${ }^{\circledR}$ TCI Europe), $25 \mu \mathrm{L}$ sample and $25 \mu \mathrm{L}$ of 2,2'-azobis(2amidopropane)dihydrochloride (41.4 g.L $\left.\mathrm{L}^{-1}\right)$. The blank contained $25 \mu \mathrm{L} 75 \mathrm{mM}$ phosphate buffer (pH 7.4) instaed of sample, whereas the standards contained $25 \mu \mathrm{L}$ of 10 to $50 \mu \mathrm{M}$ 6-hydroxy-2,5,7,8- 
tetramethylchroman-2-carboxylic acid (Trolox $\left.{ }^{\circledR}\right)$ in place of the sample. The fluorescent emission at $515 \mathrm{~nm}$ was then monitored kinetically during $30 \mathrm{~min}$ at $37{ }^{\circ} \mathrm{C}$, after excitation at $493 \mathrm{~nm}$ using a FLx800 Fluorescence Microplate Reader (Biotek). The final results were calculated using the area differences under the fluorescence decay curves between the blank and the sample, and were expressed as mM Trolox equivalents per $\mathrm{g}$ of dry weight of plant material (mM TE. $100 \mathrm{~g}^{-1} \mathrm{dw}$ ).

\subsection{HPLC-MS Phenolic Profile Determination}

Phenolic extracts were dried by rotary evaporation, ressuspended in $5 \%(\mathrm{v} / \mathrm{v})$ acetonitrile in water and was analyzed on a LCQ-DECA system controlled by the XCALIBUR software (2.0, ThermoFinnigan). The LCQ-Deca system comprised a Surveyor autosampler, pump and photo diode array detector (PDAD) and a Thermo Finnigan mass spectrometer iontrap. The PDA collected spectral data from 200-600 nm and scanned three discrete channels (at 280, 365 and $510 \mathrm{~nm}$ ). The samples were applied to a C-18 column (Synergi Hydro C18 column with polar end capping, $4.6 \mathrm{~mm} \times 150$ mm, Phenomonex Ltd.) and eluted over a gradient of 95:5 solvent A:B at time $=0$ minutes to $60: 40$ $\mathrm{A}: \mathrm{B}$ at time $=60$ minutes at a flow rate of $400 \mu \mathrm{L} / \mathrm{min}$. Solvent A was $0.1 \%(\mathrm{v} / \mathrm{v})$ formic acid in ultra pure water and solvent B $0.1 \%(\mathrm{v} / \mathrm{v})$ formic acid in acetonitrile. The LCQ-Deca LC-MS was fitted with an ESI (electrospray ionization) interface and analyzed the samples in positive and negative-ion mode. Two scan events, full scan analysis in mass range $80-2000 \mathrm{~m} / \mathrm{z}$ followed by data dependent MS/MS of the most intense ions, were used for compounds detection and identification. The data-dependent MS/MS used collision energies (source voltage) of $45 \%$. The capillary temperature was set at $275{ }^{\circ} \mathrm{C}$ with sheath gas at $60 \mathrm{psi}$ and auxiliary gas at 10 psi. Before the analysis, the system was tuned by using known concentrations of cyanidin-3-glucoside (positive mode) and quercetin-3-glucoside (negative mode) in ultrapure water.

\subsection{Cell Culture}

Human neuroblastoma SK-N-MC cells were obtained from the European Collection of Cell Cultures (ECACC) and cultured in EMEM supplemented with $2 \mathrm{mM}$ Glutamine, 10\% (v/v) heatinactivated fetal bovine serum (Gibco), 1\% (w/v) of non-essential amino acids and sodium pyruvate $(1 \mathrm{mM})$. The cells were maintained at $37^{\circ} \mathrm{C}$ in $5 \% \mathrm{CO}_{2}$. All experiments were carried out $24-48 \mathrm{~h}$ after cells were seeded.

\subsection{Cell Viability}

Hydroethanolic extracts were prepared as described above, dried under vacuum and solubilized in cell medium for the cytotoxicity tests. The test was performed by a 96-well plate cell viability assay on the neuroblastoma human cell line SK-N-MC, to identify the nontoxic range of extract concentrations. Toxicity tests involved a $4 \mathrm{~h}$ incubation in the range 0 to $500 \mu \mathrm{g}$ GAE. $\mathrm{mL}^{-1}$ medium. Cell viability was assessed using the CellTiter-Blue ${ }^{\circledR}$ Cell Viability Assay, a fluorescent method based on the ability of living cells to convert a non-fluorescent redox dye (resazurin) into a fluorescent end product 
(resorufin), according to the manufacture instructions. Nonviable cells rapidly lose their metabolic capacity and thus do not generate the fluorescent signal.

\subsection{Intracellular Antioxidant Activity}

Neuroblastoma cells were pre-incubated for $1 \mathrm{~h}$ with strawberry tree or raspberry fruit extracts and then were treated with $\mathrm{H}_{2} \mathrm{O}_{2}(1 \mathrm{mM})$ for $1.5 \mathrm{~h}$. Fruit hydroethanolic extracts were prepared as described above, dried under vacuum and dissolved in cell medium. Cell viability was evaluated as described above.

\subsection{Statistical Analysis}

The results reported in this work are the averages of at least three independent experiments and are represented as the mean \pm SD. Differences among treatments were detected by analysis of variance [30] with Tukey HSD (Honest Significant Difference) multiple comparison test $(\alpha=0.05)$ using SigmaStat 3.10 (Systat).

\section{Conclusions}

The involvement of free radicals, specially their increased production, appears to be a common feature to most human diseases, including cardiovascular disease, neurodegeneration and cancer. As such, dietary antioxidants have been suggested to be particularly important tools to fight against these diseases, by affording protection towards free radical damage in cellular DNA, lipids and proteins. In Rubus species an attempt has been made to rationalize the antioxidant potential in terms of the phenolic compounds present [18]. In all samples analyzed, ascorbic acid was found to make only a minor contribution (3\%) to the total antioxidant capacity; the majority of the antioxidant capacity thus appeared to be due to flavonoids, the dominant family of phenolic compounds [18].

Although the chemically-determined antioxidant characterization of berries is important, evidence for their biological significance in human diseases and homeostasis is lacking. Therefore, the validation of these bioactivities in different cell-based human-disease model assays is very important, together with information on the bioavailability and metabolism of these phytomolecules.

In this study, a neurodegeneration cell model was used to evaluate the neuroprotective effect of the strawberry tree and raspberry fruit phenolics. The neuroblastoma cell line SK-N-MC was subjected to an oxidative stress after pre-incubation with the fruits extracts. Although the measured chemical antioxidant activity exhibited by strawberry tree fruit was comparable to that presented by raspberry, the latter could increase cell survival by $36.6 \%$ while no effect in neuroblastoma viability was detected with the former. These results clearly demonstrate that an interesting level of chemically-determined antioxidant activity present in a plant extract is not necessarily correlated with biological significance, as concluded by the effect of strawberry tree fruit on a neurodegeneration cell model.

It is clearly evident that many more cell and organism assays should be performed to validate previously detected chemical bioactivities. As a whole, the results presented in this work show that 
there is no protective effect of strawberry tree berry phenolics on a neurodegeneration cell model, but do not exclude other possible relevant biological effects.

\section{Acknowledgements}

To Action Cost 863 for financial support of SF to attend to the International Conference on FoodOmics, and to FCT for financial support of CS (SRFH/BPD/26562/2006) and LT (SFRH/BD/37382/2007). DS and GM thank Scottish Government Rural and Environment Research and Analysis Directorate (RERAD) for support. We also would like to acknowledge Pedro Oliveira for providing Rubus idaeus fruits from Herdade Experimental da Fataca.

\section{References and Notes}

1. Dore S. Unique properties of polyphenol stilbenes in the brain: More than direct antioxidant actions; gene/protein regulatory activity. Neurosignals 2005, 14, 61-70.

2. Mandel S.; Youdim M.B. Catechin polyphenols: Neurodegeneration and neuroprotection in neurodegenerative diseases. Free Radic. Biol. Med. 2004, 37, 304-317.

3. Butterfield D.A. Amyloid beta-peptide (1-42)-induced oxidative stress and neurotoxicity: Implications for neurodegeneration in alzheimer's disease brain. A review. Free Radic. Res. 2002, 36, 1307-1313.

4. Andres-Lacueva C.; Shukitt-Hale B.; Galli R.L.; Jauregui O.; Lamuela-Raventos R.M.; Joseph J.A. Anthocyanins in aged blueberry-fed rats are found centrally and may enhance memory. Nutr. Neurosci. 2005, 8, 111-120.

5. Bickford P.C.; Gould T.; Briederick L.; Chadman K.; Pollock A.; Young D., et al. Antioxidantrich diets improve cerebellar physiology and motor learning in aged rats. Brain Res. 2000, 866, 211-217.

6. Lau F.C.; Shukitt-Hale B.; Joseph J.A. Beneficial effects of berry fruit polyphenols on neuronal and behavioral aging. J. Sci. Food Agric. 2006, 86, 2251-2255.

7. Shukitt-Hale B.; Lau F.C.; Joseph J.A. Berry fruit supplementation and the aging brain. J. Agric. Food Chem. 2008, 56, 636-641.

8. Ayaz F.A.; Kucukislamoglu M.; Reunanen M. Sugar, non-volatile and phenolic acids composition of strawberry tree (Arbutus unedo L. var.Ellipsoidea) fruits. J. Food Comp. Anal. 2000, 13, 171-177.

9. Alarcao-E-Silva M.L.C.M.M.; Leitao A.E.B.; Azinheira H.G.; Leitao M.C.A. The Arbutus berry: Studies on its color and chemical characteristics at two mature stages. J. Food Comp. Anal. 2001, 14, 27-35.

10. Pallauf K.; Rivas-Gonzalo J.C.; del Castillo M.D.; Cano M.P.; de Pascual-Teresa S. Characterization of the antioxidant composition of strawberry tree (Arbutus unedo L.) fruits. J. Food Comp. Anal. 2008, 21, 273-281.

11. Bnouham M.; Merhfour F.Z.; Legssyer A.; Mekhfi H.; Maallem S.; Ziyyat A. Antihyperglycemic activity of Arbutus unedo, Ammoides pusilla and Thymelaea hirsuta. Pharmazie. 2007, 62, 630-632. 
12. Pawlowska A.M.; De Leo M.; Braca A. Phenolics of Arbutus unedo L. (ericaceae) fruits: Identification of anthocyanins and gallic acid derivatives. J. Agric. Food Chem. 2006, 54, 10234-10238.

13. Males Z.; Plazibat M.; Vundac V.B.; Zuntar I. Qualitative and quantitative analysis of flavonoids of the strawberry tree-Arbutus unedo L. (ericaceae). Acta Pharm. 2006, 56, 245-250.

14. Ross H.A.; McDougall G.J.; Stewart D. Antiproliferative activity is predominantly associated with ellagitannins in raspberry extracts. Phytochemistry 2007, 68, 218-228.

15. Rouanet J.-M.; Décordé K.; Rio D.D.; Auger C.; Borges G.; Cristol J.-P.; Lean, M.E.J.; Crozier, A. Berry juices, teas, antioxidants and the prevention of atherosclerosis in hamsters. Food Chem. 2010, 118, 266-271.

16. Zhang L.; Li J.; Hogan S.; Chung H.; Welbaum G.E.; Zhou K. Inhibitory effect of raspberries on starch digestive enzyme and their antioxidant properties and phenolic composition. Food Chem. in Press.

17. Linden A.; Gulden M.; Martin H.J.; Maser E.; Seibert H. Peroxide-induced cell death and lipid peroxidation in c6 glioma cells. Toxicol. In Vitro 2008, 22, 1371-1376.

18. Deighton N.; Brennan R.; Finn C.; Davies H.V. Antioxidant properties of domesticated and wild Rubus species. J. Sci. Food Agric. 2000, 80, 1307-1313.

19. Wang S.Y.; Lin H.S. Antioxidant activity in fruits and leaves of blackberry, raspberry, and strawberry varies with cultivar and developmental stage. J. Agric. Food Chem. 2000, 48, 140-146.

20. Rice-Evans C.A.; Miller N.J.; Bolwell P.G.; Bramley P.M.; Pridham J.B. The relative antioxidant activities of plant-derived polyphenolic flavonoids. Free Radic. Res. 1995, 22, 375-383.

21. Santos-Buelga C.; Scalbert A. Proanthocyanidins and tannin-like compounds - nature, occurrence, dietary intake and effects on nutrition and health. J. Sci. Food Agric. 2000, 80, 1094-1117.

22. García-Alonso M.; de Pascual-Teresa S.; Santos-Buelga C.; Rivas-Gonzalo J.C. Evaluation of the antioxidant properties of fruits. Food Chem. 2004, 84, 13-18.

23. Beekwilder J.; Jonker H.; Meesters P.; Hall R.D.; van der Meer I.M.; Ric de Vos C.H. Antioxidants in raspberry: On-line analysis links antioxidant activity to a diversity of individual metabolites. J. Agric. Food Chem. 2005, 53, 3313-3320.

24. Trewavas A.; Stewart D. Paradoxical effects of chemicals in the diet on health. Curr. Opin. Plant Biol. 2003, 6, 185-190.

25. Calabrese E.J.; Baldwin L.A. Hormesis: U-shaped dose responses and their centrality in toxicology. Trends Pharmacol Sci. 2001, 22, 285-291.

26. Calabrese E.J.; Baldwin L.A. U-shaped dose-responses in biology, toxicology, and public health. Annu. Rev. Public Health. 2001, 22, 15-33.

27. Calabrese E.J.; Baldwin L.A. Applications of hormesis in toxicology, risk assessment and chemotherapeutics. Trends Pharmacol. Sci. 2002, 23, 331-337.

28. Singleton V.L.; Rossi J.A. Colorimetry of total phenolics with phosphomolybdic-phosphotungstic acid reagents. Am. J. Enol. Vitic. 1965, 16, 144-158.

29. Cao G.; Alessio H.M.; Cutler R.G. Oxygen-radical absorbance capacity assay for antioxidants. Free Rad. Biol. Med. 1993, 14, 303-311. 
30. Popova M.; Bankova V.; Butovska D.; Petkov V.; Nikolova-Damyanova B.; Sabatini A.G., et al. Validated methods for the quantification of biologically active constituents of poplar-type propolis. Phytochem. Anal. 2004, 15, 235-240.

\section{Appendix}

Table 1. Peak assignments, retention times and mass spectral data of phenols present in $A$. unedo fruit extract.

\begin{tabular}{|c|c|c|c|c|c|}
\hline $\begin{array}{c}\text { Peak } \\
\text { No. }\end{array}$ & RT & PDA & $\mathbf{M} / \mathbf{Z}[\mathbf{M}-\mathbf{H}]$ & $\mathbf{M S}^{2}$ & Putative identity \\
\hline 1 & 7.37 & 280 & 331.1 & $\mathbf{2 7 1 . 0}, 211.1, \mathbf{1 6 9 . 0}$ & Gallic acid glucoside \\
\hline 2 & 8.70 & 265 & 331.1 & $\mathbf{1 6 9 . 0}, 125.0$ & Galloyl glucoside \\
\hline 3 & 10.64 & 270 & 343.0 & $191.2,169.0$ & 3-O- or 5-O-galloylquinic acid [12] \\
\hline 4 & 14.04 & $\begin{array}{l}255- \\
300\end{array}$ & 331.1 & 169.1 & 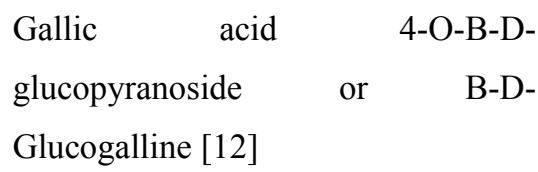 \\
\hline 5 & 16.29 & $\begin{array}{l}255- \\
300\end{array}$ & 325.0 & $169.0,125.1$ & Galloyl shikimic acid \\
\hline 6 & 20.93 & 280 & 577.1 & 289.2 & Proanthocyanidin dimer [12] \\
\hline 7 & 21.36 & $\begin{array}{l}270- \\
290\end{array}$ & $495.0,465.0,343.0,191.2$ & 343.0, 191.0 & Digalloylquinic acid \\
\hline 8 & 21.95 & 295 & $495.0,465.0,343.0,191.2$ & 343.0, 191.0 & Isomer of digalloylquinic acid \\
\hline 9 & 22.66 & 280 & $577.0,423.2,407.2,289.2$ & $425.0,407.2,289.2$ & Procyanidin dimer B2 [10] \\
\hline 10 & 23.86 & 280 & 289.1 & $261.0,175.0$ & Catechin \\
\hline 11 & 24.31 & 320 & $865.1,453.2,325.1$ & 577.1 & Procyanidin trimer \\
\hline 12 & 24.6 & 285 & $\begin{array}{l}541.1, \quad 483.1, \quad 467.3, \quad 321.0 \\
301.2\end{array}$ & $453.1,301.4,169.2$ & Gallic acid derivative \\
\hline 13 & 25.50 & $\begin{array}{l}280 \\
525\end{array}$ & 477.0, 325.1 & $325.0,169.0$ & Digalloyl shikimic acid \\
\hline 14 & 26.10 & 275 & 477.0, 325.1 & $325.0,169.0$ & Digalloyl shikimic acid \\
\hline 15 & 26.84 & 270 & $\mathbf{6 3 3 . 1}, 463.1,301.2,275.2$ & $463.0,301.1$ & Strictinin ellagitannin \\
\hline 16 & 28.68 & 360 & 463.2, 301.3 & 301.2 & Quercetin-3-glucoside \\
\hline 17 & 29.44 & 275 & $\begin{array}{l}\text { 1109.0, 972.9, 647.0, 635.1, } \\
588.1,441.0,301.3\end{array}$ & $783.1,492.8$ & Gallotannin derivative \\
\hline 18 & 31.09 & 280 & 366.2, 186.0 & 204.1, $186.1,142.0$ & Unknown \\
\hline 19 & 33.08 & 275 & 953.0 & $633.0,463.2,301.2$ & Tannin \\
\hline 20 & 33.36 & 360 & $433.1,301.2$ & 301.0 & Quercetin-3-xyloside \\
\hline 21 & 34.67 & $\begin{array}{l}260- \\
355\end{array}$ & $615.2,463.2,433.1,301.1$ & $463.0,301.1$ & Quercetin hexose galloyl derivative \\
\hline 22 & 35.21 & $\begin{array}{l}260- \\
355\end{array}$ & $615.2,463.2,433.1,301.1$ & $463.0,301.1$ & Quercetin hexose galloyl derivative \\
\hline
\end{tabular}


Table 1. Cont.

\begin{tabular}{|c|c|c|c|c|c|}
\hline 23 & 36.30 & $\begin{array}{r}260- \\
355\end{array}$ & $615.2,463.2,433.1,301.1$ & $463.0,301.1$ & Quercetin hexose galloyl derivative \\
\hline 24 & 36.69 & $\begin{array}{l}255 \\
370\end{array}$ & 301.2 & $301.2,257.2$ & Ellagic acid \\
\hline 25 & 36.96 & 345 & $463.1,301.2$ & 301.2 & Quercetin 3-galactoside \\
\hline 26 & 37.40 & $\begin{array}{l}275- \\
355\end{array}$ & 463.1, 301.2 & 301.2 & Quercetin 3-glucoside \\
\hline 27 & 38.09 & 280 & $\begin{array}{l}\text { 939.1, 769.1, 729.0, 617.1, } \\
544.2,480.2,469.2\end{array}$ & $769.0,617.2$ & Gallotannin \\
\hline 28 & 39.81 & 355 & $\mathbf{5 9 9 . 0 ,} 301.0$ & $463.1,301.1$ & Ellagic acid-hexose derivative \\
\hline 29 & 40.75 & 355 & 433.0, 301.1 & 301.1 & Ellagic acid arabinoside/xyloside \\
\hline 30 & 41.49 & 355 & 447.0, 301.1 & 301.1 & Ellagic acid rhamnoside \\
\hline
\end{tabular}

The most abundant ions are shown in bold. Numbers in brackets indicate references

Table 2. Peak assignments, retention times and mass spectral data of anthocyanins present in A. unedo fruit extract.

\begin{tabular}{ccllll}
\hline Peak No. & RT & \multicolumn{1}{c}{ PDA } & \multicolumn{1}{c}{ M/Z [M+H] } & MS2 & \multicolumn{1}{c}{ Putative identity } \\
\hline \multirow{2}{*}{ A1 } & 20.60 & 280,525 & $\mathbf{5 7 9 . 1 , \quad 4 6 5 . 1 ,}$ & 303.2 & $\begin{array}{l}\text { Delphinidin-3-glucoside or delphinidin-3-galactoside } \\
\end{array}$ \\
A2 & 22.94 & 280,515 & $\mathbf{4 4 9 . 0 , 2 8 7 . 2}$ & 287.2 & Cyanidin 3-O-glucoside or cyanidin-3-galactoside [10] \\
A3 & 25.28 & 280,515 & $\mathbf{4 1 9 . 1 , 2 8 7 . 2}$ & 287.2 & Cyanidin 3-O-arabinoside [10] \\
\hline
\end{tabular}

The most abundant ions are shown in bold. Numbers in brackets are references. 
Figure 1. HPLC phenolic profile assessed for A. unedo fruit extract. The chromatogram in (A) shows the absorbance of peaks at $280 \mathrm{~nm}$, (B) peaks at $365 \mathrm{~nm}$ and (C) peaks at 520 $\mathrm{nm}$. The peaks are numbered and assignments are given in Table 3 for phenols and Table 4 for anthocyanins.

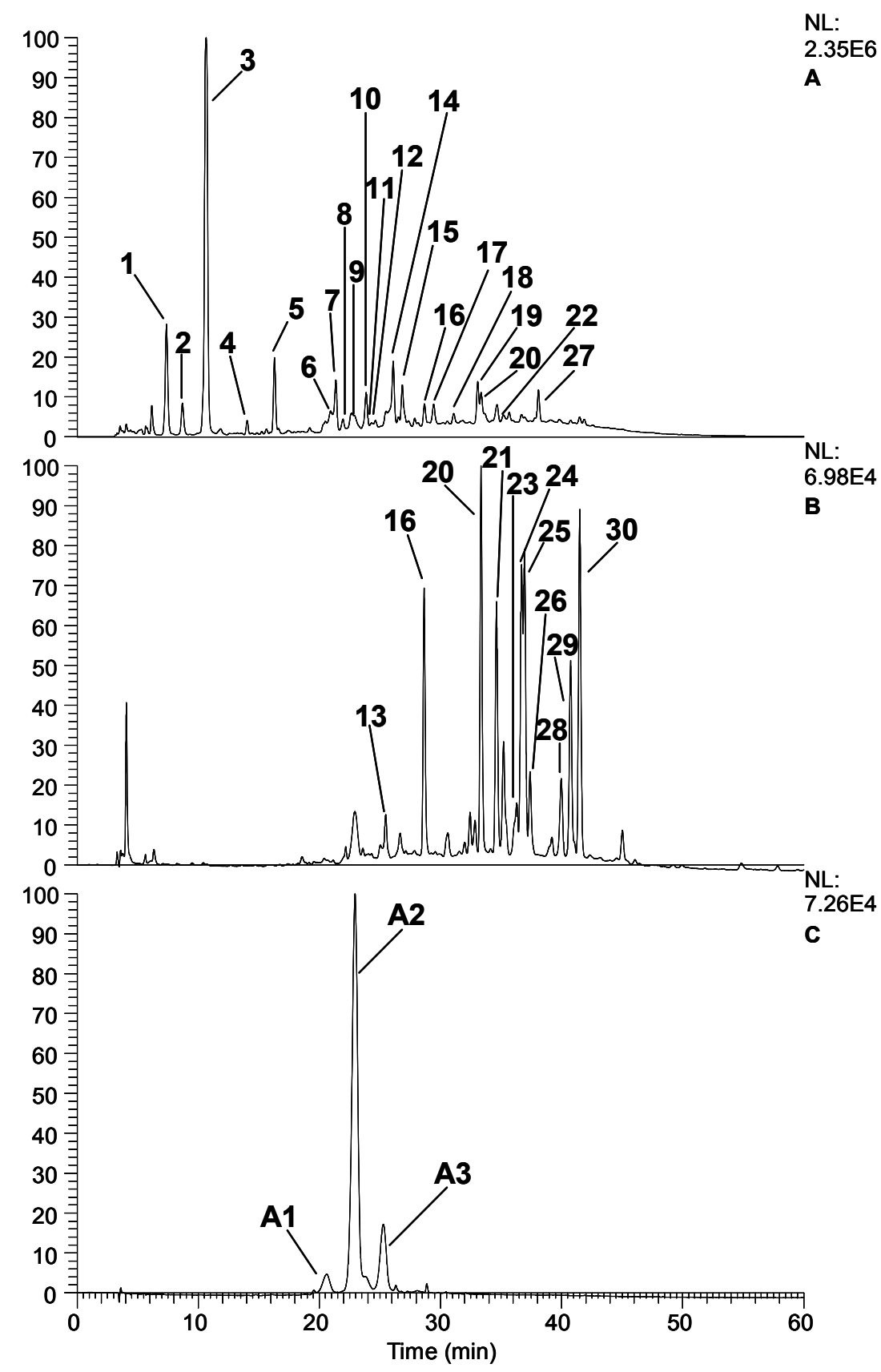


Table 3. Peak assignments, retention times and mass spectral data of phenols present in $R$. idaeus fruit extract.

\begin{tabular}{|c|c|c|c|c|c|}
\hline $\begin{array}{c}\text { Peak } \\
\text { No. }\end{array}$ & $\mathbf{R T}$ & PDA & $\mathbf{M} / \mathbf{Z}[\mathbf{M}-\mathbf{H}]$ & $\mathbf{M S}^{2}$ & Putative identity \\
\hline 1 & 23.03 & 265 & $\begin{array}{l}\text { 1250.8, } 609.3, \quad 444.9, \quad 323.0, \quad 301.2, \\
224.83,136.7\end{array}$ & ND & Ellagitannin \\
\hline 2 & 24.43 & 340 & $\mathbf{6 2 7 . 1}, 593.1,491.2,285.1$ & $517.1, \mathbf{2 8 5 . 1}$ & Unknown \\
\hline 3 & 25.68 & $\begin{array}{l}280 \\
365\end{array}$ & $\mathbf{5 7 7 . 1}, 465.1,407.2,289.2$ & 289.2 & Proanthocyanidin dimer \\
\hline 4 & 27.25 & 260 & $1566.9,1265.0, \mathbf{7 8 3 . 3}, 633.2,301.2$ & 481.0, 301.2 & Ellagitannin \\
\hline 5 & 28.04 & $\begin{array}{l}280 \\
340\end{array}$ & 289.2 & $289.0,245.1$ & Epicatechin \\
\hline 6 & 30.36 & 250 & $\begin{array}{l}\text { 1868.9, 1567.0, 1401.3, 1250.3, 934.1, } \\
633.1,301.2\end{array}$ & $\begin{array}{l}1567.0,1250.0,932.6, \\
897.0\end{array}$ & Lambertianin $\mathrm{C}$ \\
\hline 7 & 31.16 & 360 & 625.2, 301.2 & 301.1 & Ellagic acid diglucoside \\
\hline 8 & 31.50 & 250 & $\begin{array}{l}\text { 1868.9, } 1567.0,1235.0,934.3,633.2, \\
301.2\end{array}$ & $\begin{array}{l}1566.9,1235.2,933.1, \\
897.0\end{array}$ & Sanguiin H6 \\
\hline 9 & 33.22 & 360 & $433.1,301.2$ & 301.2 & Ellagic acid arabinoside \\
\hline 10 & 36.57 & 370 & 301.2 & 301.2 & Ellagic acid \\
\hline 11 & 37.31 & 345 & 477.0, 463.1, 301.2 & 301.2 & $\begin{array}{l}\text { Quercetin-3- } \\
\text { glucuronide }\end{array}$ \\
\hline 12 & 39.62 & 360 & 447.1, 315.1, 300.1 & 315.1 & $\begin{array}{l}\text { Methyl ellagic acid } \\
\text { conjugate }\end{array}$ \\
\hline
\end{tabular}

The most abundant ions are shown in bold; ND- Not detected.

Table 4. Peak assignments, retention times and mass spectral data of anthocyanins present in $R$. idaeus fruit extract.

\begin{tabular}{ccclll}
\hline Peak No. & RT & PDA & $\mathbf{M} / \mathbf{Z}[\mathbf{M}+\mathbf{H}]$ & \multicolumn{1}{c}{$\mathbf{M S}^{\mathbf{2}}$} & \multicolumn{1}{c}{ Putative identity } \\
\hline A1 & 26.17 & 280,515 & $\mathbf{6 1 1 . 1}$ & 287.2 & Cyanidin-3-sophoroside \\
A2 & 27.79 & 275,515 & $\mathbf{5 9 5 . 1}$ & $449.1,287.3$ & Cyanidin-3-rutinoside \\
\hline
\end{tabular}

The most abundant ions are shown in bold. 
Figure 2. HPLC phenolic profile assessed for R. idaeus fruit extract. The chromatogram in (A) shows the absorbance of peaks at $280 \mathrm{~nm}$, (B) peaks at $365 \mathrm{~nm}$ and (C) peaks at 520 $\mathrm{nm}$. The peaks are numbered and assignments are given in Table 1 for phenols and Table 2 for anthocyanins.

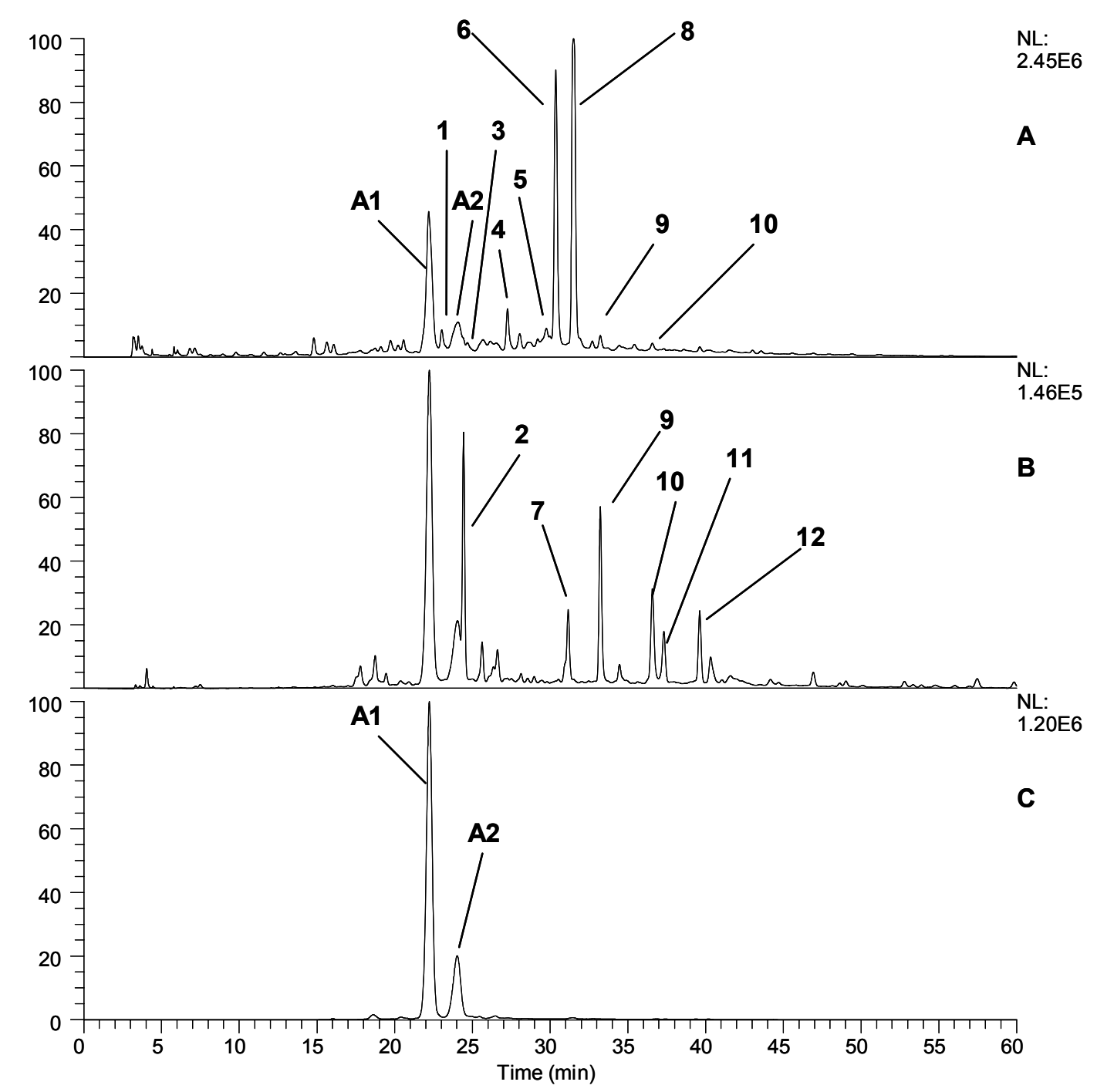

(C) 2010 by the authors; licensee Molecular Diversity Preservation International, Basel, Switzerland. This article is an open-access article distributed under the terms and conditions of the Creative Commons Attribution license (http://creativecommons.org/licenses/by/3.0/). 